\title{
Primary Ewing's sarcoma in a small intestine - a case report and review of the literature
}

\author{
Andrej Kolosov, Audrius Dulskas ${ }^{*}$ [D, Kastytis Pauza, Veslava Selichova, Dmitrij Seinin and Eugenijus Stratilatovas
}

\begin{abstract}
Background: Ewing's sarcoma usually presents in paediatric patients with its primary location being bone tissue. Nevertheless, we present such an adult case which arises from the small intestine. We registered thirty one cases of such origin published so far excluding ours.

Case presentation: We report a case of 30 year old female who was admitted due to the persistent anaemia. Whole body computed tomography scan revealed abdominal mass in her left upper abdominal compartment. Surgery on the mass originating from jejunum was performed, although due to extremely complicated postoperative period and rapid dissemination no additional therapy had been performed. The tumour was positive for CD99, ERG, CD56, Synaptophysin, PanCK, Cam5.2.

Conclusion: Extraosseus Ewing's sarcoma is extremely rare entity, with poor prognosis.

Keywords: Ewing's sarcoma, Extraosseus sarcoma, Primitive neuroectodermal tumor, Small bowel sarcoma, ERG-FUS translocation
\end{abstract}

\section{Background}

Ewing's sarcoma was first identified by A.P. Stout in 1918 [1]. Genetically Ewing's sarcoma is determined by recurrent balanced translocations involving the EWSR1 gene on chromosome 22 and members of the E-twenty six (ETS) family of transcription factor genes [2-4]. It includes extra-osseous (also called extra-skeletal) Ewing's sarcoma, peripheral neuroepithelioma, Askin's tumour (tumour of chest wall), and peripheral neuroblastoma $[4,5]$. Primitive neuroectodermal tumours (PNET) are also referred as Ewing's sarcoma [6]. Histologically they are presented as small round cell tumours which originate

\footnotetext{
*Correspondence: audrius.dulskas@gmail.com

Vilnius University, Faculty of Medicine, Vilnius, Lithuania
}

from the bone and soft tissue [7]. Nevertheless they can be found in most organs: chest (44\%), retroperitoneum and pelvis (26\%), extremities (20\%), head and neck (6\%), kidneys, oesophagus, ovaries, prostate [5-10] and are especially rare in small bowel [7]. To make matters clearer, they are divided into pPNET (peripheral primitive neuroectodermal tumours), CNS primitive neuroectodermal tumours (PNETs) and neuroblastoma [11]. While microscoping pPNET looks almost identical to the tumours originating from the bone [12] which makes them hard to differentiate especially when it originates near the bone. In all cases Ewing's sarcoma metastasises rapidly disregarding its origin [13]. It usually occurs in young patients, with paediatric patients being a second most common tumour in this age group [5, 12-15]. In older patients survival rate is lower and there are 
more cases with metastatic spread or extra skeletal tumours [3]. The common sites of Ewing's sarcoma recurrence are the soft tissue of the lower extremities, paravertebral region, and pelvis [14]. Five year overall survival rate is $44 \%$ (ranging 20 $60 \%)[16]$.

Table 1 Clinical characteristics and outcomes of patients with intestinal Ewing sarcoma

\begin{tabular}{|c|c|c|c|c|c|c|}
\hline Author, year & Sex & $\begin{array}{l}\text { Age, } \\
y\end{array}$ & Part of small intestine & Treatment & $\begin{array}{l}\text { Survival, } \\
\text { months }\end{array}$ & $\begin{array}{l}\text { MTS on } \\
\text { diagnosis }\end{array}$ \\
\hline Horie, 2000 [15] & M & 40 & Mesentery of jejunum & Surgery - > systemic therapy & 5 & N/A \\
\hline Shek, 2001 [9] & $\mathrm{F}$ & 9 & $\begin{array}{l}\text { Mesentery of the small } \\
\text { bowel }\end{array}$ & $\begin{array}{l}\text { Surgery- > systemic therapy - > surgery- > } \\
\text { systemic therapy }\end{array}$ & 25 & pelvis \\
\hline Saranganathan, 2001 [17] & $M$ & 13 & Jejunum & Surgery & $12+$ & Absent \\
\hline $\begin{array}{l}\text { Balasubramanian, } 2002 \\
{[16]}\end{array}$ & $\mathrm{F}$ & 53 & Mesentery of ileum & Surgery & $\mathrm{N} / \mathrm{A}$ & $\mathrm{N} / \mathrm{A}$ \\
\hline Graham, 2002 [2] & $M$ & 14 & Distal ileum & Surgery- > systemic therapy & $52+$ & $\mathrm{N} / \mathrm{A}$ \\
\hline Boehm, 2003 [18] & M & 18 & lleum & $\begin{array}{l}\text { Surgery- > systemic therapy - > regression - > } \\
\text { systemic therapy, autologous cell Tx }\end{array}$ & + & peritoneum \\
\hline Bala, $2006[8]$ & $\mathrm{F}$ & 57 & Terminal ileum & Surgery- > systemic therapy & $8+$ & $\mathrm{N} / \mathrm{A}$ \\
\hline Batziou, 2006 [12] & M & 66 & Small intestine & $2 x$ surgery - $>4$ systemic therapy & $48+$ & $\mathrm{N} / \mathrm{A}$ \\
\hline Kim, 2007 [14] & M & 63 & $\begin{array}{l}\text { Terminal ileum and } \\
\text { jejunum }\end{array}$ & Surgery- > systemic therapy & N/A & Regional I/n \\
\hline Sethi, 2007 & M & 44 & Terminal ileum & Surgery- $>6$ courses systemic therapy & 13 & $\mathrm{~N} / \mathrm{A}$ \\
\hline Rodarte-Shade, 2012 [19] & M & 32 & lleum & Surgery- > systemic therapy & $6+$ & Absent \\
\hline Vignali, 2012 [20] & $\mathrm{F}$ & 15 & Terminal ileum, mesentery & Surgery- > systemic therapy & $\mathrm{N} / \mathrm{A}$ & $\mathrm{N} / \mathrm{A}$ \\
\hline Kim, $2013[4]$ & M & 23 & Mesentery of jejunum & Surgery- > systemic therapy - > surgery & $N / A$ & $\begin{array}{l}\text { Porta hepatis, I/ } \\
\mathrm{n}\end{array}$ \\
\hline Rachan Shetty, 2014 & $\mathrm{~F}$ & 24 & lleum & Surgery - > systemic therapy & $15+$ & N/A \\
\hline Milione, 2014 [3] & M & 18 & lleum & Core biopsy & 8 & Liver \\
\hline Milione, 2014 [3] & $M$ & 20 & lleum & Core biopsy & 28 & Liver \\
\hline Milione, 2014 [3] & M & 42 & lleum & Surgery - > systemic therapy & 11 & Absent \\
\hline Milione, 2014 [3] & $M$ & 45 & lleum & Surgery - > systemic therapy & 13 & Absent \\
\hline Milione, 2014 [3] & $F$ & 15 & lleum & Surgery - > systemic therapy + radiotherapy & 28 & Absent \\
\hline Milione, 2014 [3] & M & 57 & lleum & Surgery & + & Absent \\
\hline Milione, 2014 [3] & $\mathrm{F}$ & 28 & lleum & Surgery & $204+$ & Liver \\
\hline Peng, 2015 [13] & M & 59 & $\begin{array}{l}\text { Mesentery of terminal } \\
\text { ileum }\end{array}$ & Surgery - > no adjuvant therapy & $\mathrm{N} / \mathrm{A}$ & $\mathrm{N} / \mathrm{A}$ \\
\hline Peng, 2015 [13] & M & 22 & lleum & Surgery - > no adjuvant therapy & N/A & Liver \\
\hline Peng, 2015 [13] & $\mathrm{F}$ & 36 & Mesentery of ileum & Surgery - $>8$ cycles systemic therapy & 34 & $\mathrm{~N} / \mathrm{A}$ \\
\hline Padma, 2015 [5] & $\mathrm{F}$ & 22 & Distal jejunum & Surgery & $\mathrm{N} / \mathrm{A}$ & Absent \\
\hline Liu, 2015 & M & 15 & Mesentery of jejunum & Surgery & 7 & $\mathrm{~N} / \mathrm{A}$ \\
\hline Li, $2017[7]$ & $\mathrm{F}$ & 16 & lleum & Surgery & $\mathrm{N} / \mathrm{A}$ & N/A \\
\hline Kim, 2017 [10] & $\mathrm{F}$ & 9 & Jejunum & $\begin{array}{l}\text { Systemic therapy - > surgery - > adjuvant } \\
\text { therapy }\end{array}$ & N/A & peritoneum \\
\hline Liao, 2018 [21] & $\mathrm{F}$ & 25 & lleum & Surgery & + & $\mathrm{N} / \mathrm{A}$ \\
\hline Cantu, 2019 [22] & $\mathrm{F}$ & 67 & Jejunum & Surgery & $3+$ & No \\
\hline Yagnik, 2019 [11] & M & 42 & Jejunum & Surgery - > systemic therapy & + & $\mathrm{N} / \mathrm{A}$ \\
\hline Our case, 2020 & $\mathrm{~F}$ & 30 & Jejunum & Surgery & 2 & No \\
\hline
\end{tabular}

Tx - Transplant

N/A - Not available

$\mathrm{L} / \mathrm{n}$ - Lymph nodes

+- No information of death upon the last follow up 
Up to date only 31 cases of extraosseus Ewing's sarcoma arising in a small intestine are reported in the literature (Table 1).

Here we present a case of Ewing's sarcoma in a small intestine with an extremely rapid dissemination and unfortunate ending.

\section{Case presentation}

Here we present a 30 year old female admitted to local hospital complaining of mild general weakness lasting for four months. Full blood count showed severe anaemia of $54 \mathrm{~g} / \mathrm{l}$ and a mild gastric wall inflammation was seen on gastroscopy. Blood transfusion in therapeutic ward was then performed. Whole body computed tomography $(\mathrm{CT})$ scan discovered $4.7 \times 6.2 \times 6.5 \mathrm{~cm}$ non-homogenic tumour with a cystic component in a left upper abdominal compartment. Tumour had a close contact with an inferior mesenteric vein (IMV) at the long segment, near the entrance to the superior mesenteric vein (SMV) (Type A/B) without overgrowing any another surrounding organ. Gastrointestinal stromal tumour (GIST) was suspected (Figs. 1 and 2). Patient was transferred to our cancer institute and after multidisciplinary team discussion she was elected for a surgery - removal of the GIST of the jejunum. The patient had no previous medical history of other diseases, surgeries or allergies. Her initial blood test showed haemoglobin of $74.6 \mathrm{~g} / \mathrm{l}$, so additional blood transfusion was performed.

On laparotomy the tumour involving the first loop of the small intestine $(30 \mathrm{~cm}$ from the Treitz ligament), a part of uncinated process of the pancreas, IMV and inferior mesenteric artery (IMA) was found. Enlarged small intestine lymph nodes were also seen. Resection of

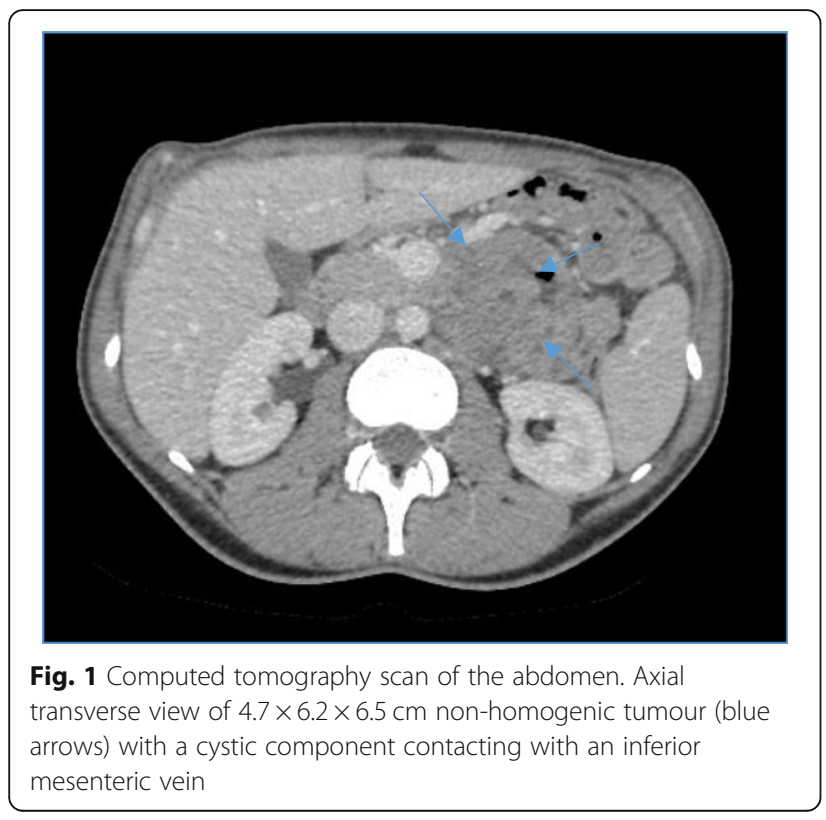

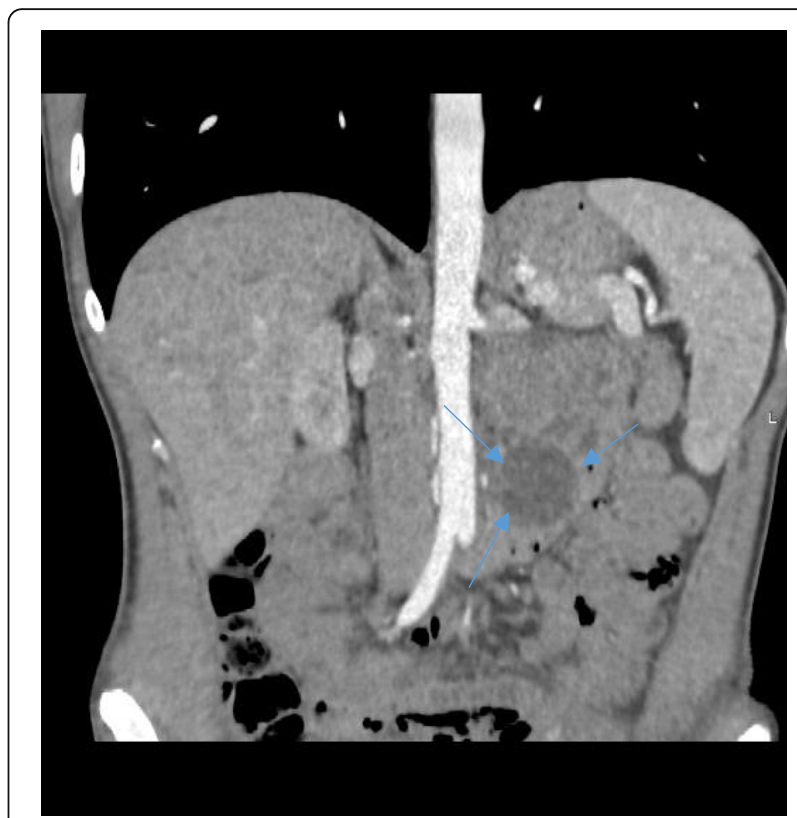

Fig. 2 Computed tomography scan of the abdomen. Coronal view $-4.7 \times 6.2 \times 6.5 \mathrm{~cm}$ non-homogenic tumour with a cystic component contacting with an inferior mesenteric vein (blue arrows)

$50 \mathrm{~cm}$ of small intestine with the tumour was performed. Two layer end-to-end entero-entero anastomosis was performed and enteral feeding tube was inserted below the anastomosis. Early postoperative course was uneventful. On postoperative day (POD) five the blood appeared through the drains - emergency surgery was initiated. Massive bleeding from superior mesenteric artery (SMA) was found and the arterial defect was sutured. The cyanotic small intestines were noticed and a partial occlusion of SMA was suspected. Aortomesenteric shunt using saphenous vein was performed and the small intestine regained its blood supply. Two days later anastomotic leak was suspected - bile from the drain was noticed. Anastomosis was resected and two layer side-to-side duodenojejunal anastomosis was performed. By then, the pathology report revealed a high grade G3 peripheral/primitive neuroectodermal tumour (PNET)/atypical Ewing sarcoma which expansion to the pancreas (Figs. 3, 4, 5, 6, 7 and 8). R1 resection (at the uncinated process of the pancreas) was confirmed (pT4N1, LVI [2]).

\section{Tumour histology}

An ulcerated tumour in small intestine wall was composed of solid sheets of small blue cells with irregular nuclear contours and prominent nucleoli. Differential diagnosis included poorly differentiated adenocarcinoma, neuroendocrine carcinoma, melanoma, lymphoma, gastrointestinal clear cell sarcoma, synovial sarcoma, 


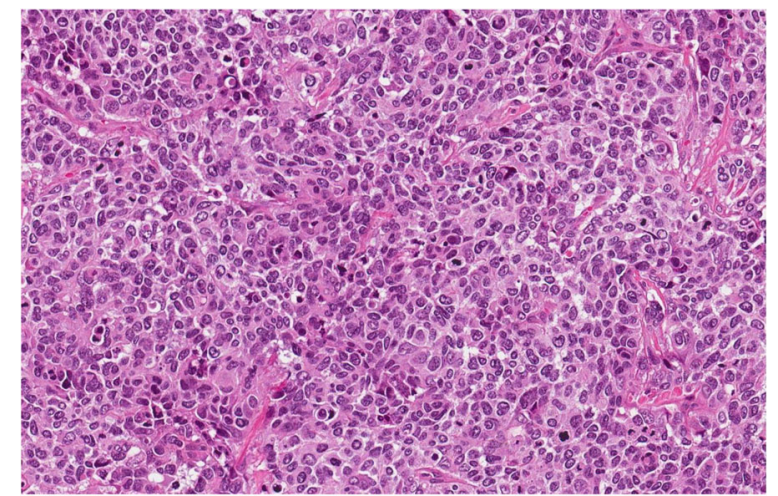

Fig. 3 Tumour is composed of sheets of mildly to moderately atypical cells with round or oval nuclei and prominent nucleoli. There were up to 60 mitoses per 10 HPF, HE 20x

rhabdomyosarcoma, epithelioid angiosarcoma, epithelioid sarcoma and germ cell tumour. Immunohistochemical tests were performed and tumour demonstrated diffuse positivity for CD99, ERG, CD56 and focal positivity for Synaptophysin, PanCK, Cam5.2. Tumour was consistently negative for LCA, SMA, Desmin, S100, HMB45, TLE1, Chromogranin A, CDX2, TTF1, PAX8, CK7, CK19, CD31, SALL4, Glucagon, Somatostatin, Gastrin and Serotonin. There was no INI1 loss. Diffuse CD99, ERG, CD56, focal PanCK, Cam5.2 and Synaptophysin immune positivity are characteristic for Ewing sarcoma family of tumours. EWSR1 (22q12) break-apart FISH test and PCR test for EWSR1-ERG, EWSR1-ETV1, EWSR1-FLI1, EWSR1-FEV, EWSR1-ETV4 translocations were performed. Unfortunately, there was no evidence of EWRS1 gene rearrangements by both FISH and PCR EWSR1 methods. Despite this fact there was no evidence of any other tumour and final diagnosis was high grade G3 peripheral/primitive neuroectodermal tumour (PNET)/atypical Ewing's sarcoma, possibly with a rare translocation.

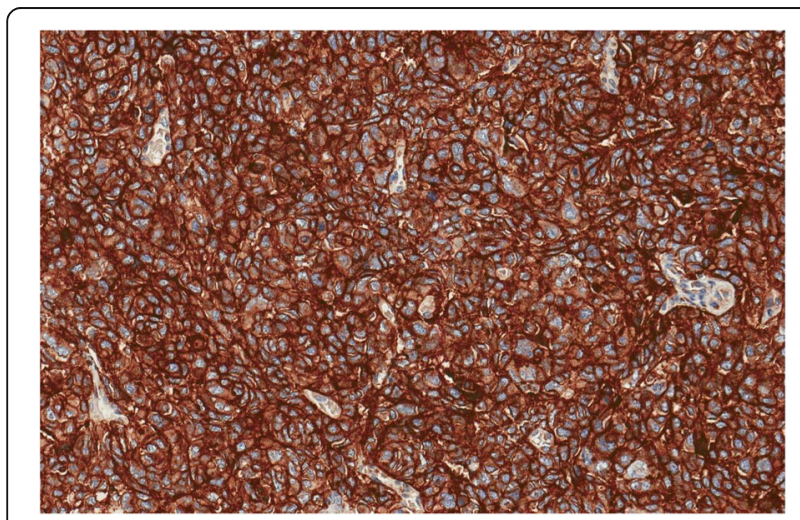

Fig. 4 Tumour showed diffuse membranous positivity for CD99

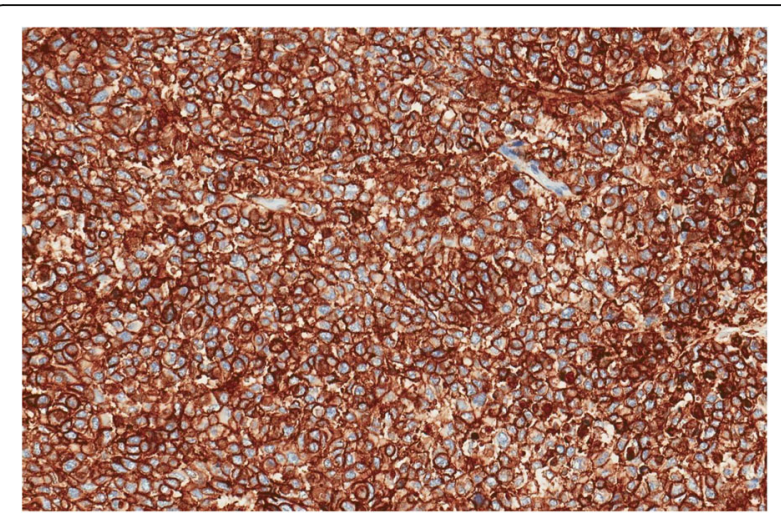

Fig. 5 Tumour showed diffuse membranous positivity CD56

\section{Postoperative period}

Eleven days after the third surgery bleeding recurred bleeding from the aorto-mesenteric shunt was found. It was sutured along its wall and intraoperative ultrasound showed reduced diameter of the shunt, and recanalized SMA. During postoperative period due to progressing bile leakage, bile ducts were catheterized trans-hepatically. Nine days later intraabdominal bleeding recurred. Bleeding from the aorta at the shunt area was found and sutured. Small intestine on the other hand showed total necrosis with multiple perforations. The changes were incompatible with life. Nonetheless $48 \mathrm{~h}$ later, patient vital signs improved and the condition stabilized. Therefore, during the next surgery necrotised small intestine was removed while closing both ends of the intestines at the demarcation lines and gastrostomy was made for the drainage of the gastric content. During the next few weeks bleeding recurred and multiple (>50) liver metastases were found. Bleeding was controlled but the patient died because of rapid dissemination of the disease.

\section{Discussion and Conclusion}

Intestinal Ewing's sarcoma as many other tumours can manifest asymptomatic although there are cases in

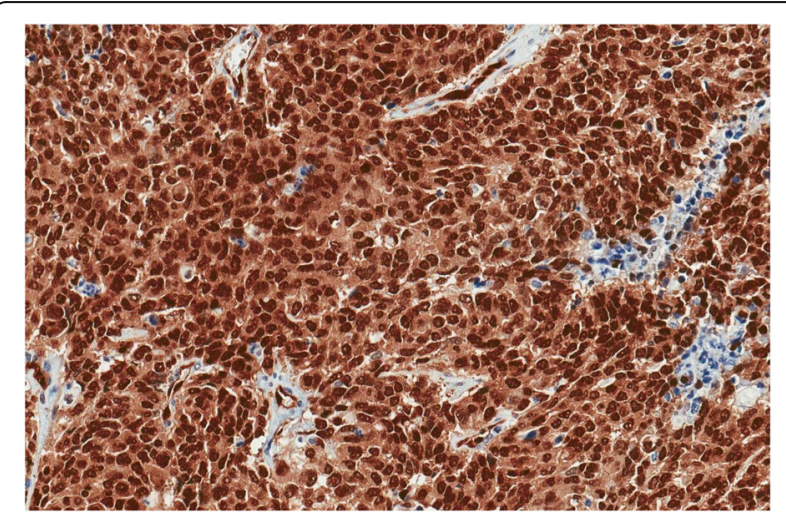

Fig. 6 Diffuse nuclear positivity for ERG 


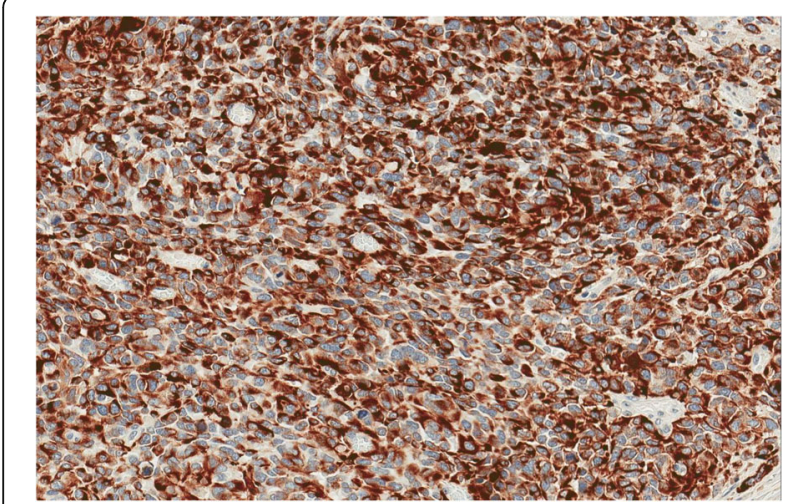

Fig. 7 Focal immunoreactions for Cam5.2

which it occurs as intussusception [18], perforation [11, 15], intestinal obstruction [14, 23], rupture [4] but usually it presents with abdominal pain or fatigue and weakness caused by mass and/or bleeding as in our case. It can be misdiagnosed as a gynaecologic pathology especially in young females as the literature shows pain can often occur in the lower abdomen [6,13,20]. Clinical presentation mainly depends on the affected site of the gastrointestinal tract [19].

Thorough examination should follow CT scan to exclude other acute diseases although there are no specific radiological signs of Ewing's sarcoma [8]. For this reason Ewing's sarcoma may initially be treated as GIST [7] as in our case.

To provide proper diagnosis, pathological examination should be carried out. It's round cell morphology is similar to neuroblastoma, malignant lymphoma, rhabdomyosarcoma, GIST, and desmoplastic small round cell tumour [14]. While Ewing's sarcoma shows rosette formation, glycogen deposition, also NSE, S-100 protein, neurosecretory-type granules [12]. In addition CD99 antigen could also be a useful tool [15]. Nowadays molecular testing is a reliable diagnostic method to diagnose ES. The most frequent translocation EWSR1-FLI1 occurs in 85\% of cases of ES [2, 22]. Second most common translocation

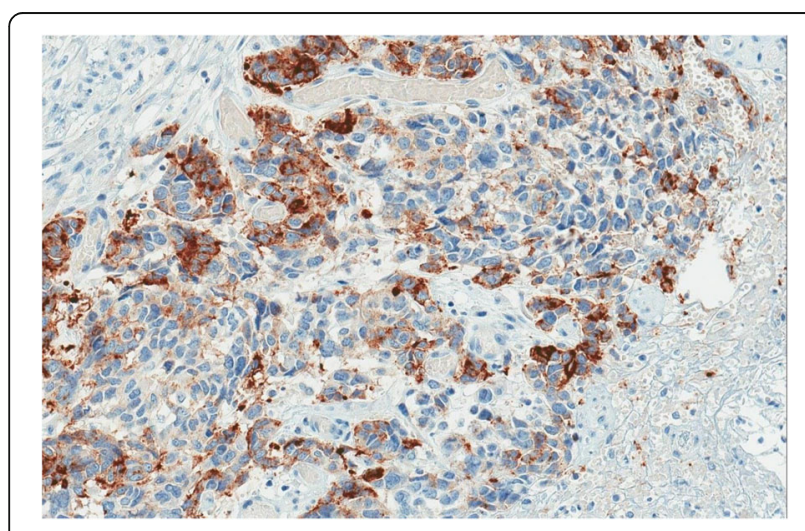

Fig. 8 Focal immunoreactions for Synaptophysin is EWSR1-ERG (5-15\%) and in such cases tumour cells are immunohistochemically positive for ERG marker. In our case ERG immunohistochemical reaction was positive, although there was no EWSR1-ERG translocation. However there is a very rare ERG-FUS translocation $(<1 \%)$, when tumour cells are also positive for ERG. We suppose that this translocation could occur in our case. It is also mentioned that fusion transcripts should not be the sole criterion of PNET [17].

All Ewing's sarcoma treatment includes local surgical and/or radiotherapy treatment followed by multidrug systemic chemotherapy $[5,7]$. It usually includes vincristine, doxorubicin, cyclophosphamide and dactinomycin [16] although of ifosfamide and etoposide were added. Latter improves outcomes in non-metastatic cases [13].

Prognosis of intestinal Ewing's sarcoma is not known as there are not enough cases. It could be compared to other sites. Although some authors do not relate tumour size with worse outcomes [13] other find $>5 \mathrm{~cm}$ size of the tumour having impact for worse survival [24]. Even in those cases surgical intervention is recommended as it decreases morbidity [21, 25]. Worse survival also may include pelvic site, older patients, poor response to chemotherapy, and metastatic disease at presentation [8] which was in our case. The main two reasons of unfortunate consequence in our case was acute pancreatitis caused by $\mathrm{R} 1$ resection at the uncinated process and a very aggressive underlying disease.

To conclude, extraosseus Ewing's sarcoma is extremely rare entity, with most often poor prognosis.

\section{Abbreviations}

ETS: E-twenty six; PNET: Primitive neuroectodermal tumours;

PPNET: peripheral primitive neuroectodermal tumour); PNETs: CNS primitive neuroectodermal tumours; CT: computed tomography; GIST: Gastrointestinal stromal tumour; IMV: inferior mesenteric vein; SMV: superior mesenteric vein; IMA: inferior mesenteric artery; SMA: superior mesenteric artery; LVI: Iympho vascular invasion; PCR: polymerase chain reaction

\section{Acknowledgements}

Not applicable.

\section{Authors' contributions}

AK analysed and interpreted the patient data regarding the previous cases. $A K$ and $A D$ performed the literature search and manuscript writing. DS and VS performed the histological examination of the tumour, and were part contributors in writing the manuscript. KP, ES performed the surgery. All authors read and approved the final manuscript.

\section{Funding \\ None.}

Availability of data and materials

Data sharing is not applicable to this article as no datasets were generated or analysed during the current study.

Ethics approval and consent to participate

The case was approved by the National Cancer Institute Review Board (No 2019.12.00073). 


\section{Consent for publication}

Written informed consent was obtained from the patient for publication of this case report and any accompanying images. A copy of the written consent is available for review by the Editor of this journal.

\section{Competing interests}

The authors declare that they have no competing interests.

Received: 26 March 2020 Accepted: 11 May 2020

Published online: 25 May 2020

\section{References}

1. Stout A. A tumor of ulnar nerve. Proc NY Pathol Soc. 1918:18:2-12.

2. Graham DK, Stork LC, Wei Q, Ingram JD, Karrer FM, Mierau GW, et al. Molecular genetic analysis of a small bowel primitive Neuroectodermal tumor. Pediatr Dev Pathol. 2002;5(1):86-90.

3. Milione M, Gasparini P, Sozzi G, Mazzaferro V, Ferrari A, Casali PG, et al. Ewing sarcoma of the small bowel: a study of seven cases, including one with the uncommonly reported EWSRT-FEV translocation. Histopathology. 2014;64(7):1014-26.

4. Kim JM, Chu YC, Choi CH, Kim L, Choi SJ, Park IS, et al. Peripheral primitive neuroectodermal tumor with osseous component of the small bowel mesentery: a case study. Korean J Pathol. 2013;47(1):77.

5. Padma M, Lakshmi RR, Kumar CK. Extraskeletal Ewing's sarcoma of the small bowel. Int J Med Sci Clin Invent. 2015;2:645-7.

6. Shetty R, Naveen JA, Premalatha CS, Lakshmaiah KC. Peripheral primitive neuroectodermal tumor of small bowel mesentry presenting as intestinal obstruction: a case report. [Internet]. [cited 2019 Oct 6]. Available from: https://www.australasiancancer.org/journal-article-view/peripheral-primitiveneuroectodermal-tumor-of-665.

7. Li T, Zhang F, Cao Y, Ning S, Bi Y, Xue W, et al. Primary Ewing's sarcoma/ primitive neuroectodermal tumor of the ileum: case report of a 16-year-old Chinese female and literature review. Diagn Pathol. 2017;12(1):37.

8. Bala M, Maly A, Remo N, Gimmon Z, Almogy G. Peripheral primitive neuroectodermal tumor of bowel mesentery in adults. Isr Med Assoc J. 2006:8(7):515-6.

9. Shek TWH, Chan GCF, Khong PL, Chung LP, Cheung ANY. Ewing sarcoma of the small intestine. J Pediatr Hematol Oncol. 2001;23(8):530-2.

10. Kim YS, Moon HM, Lee KS, Park YS, Kim HY, Kim JY, et al. Pediatric Ewing's sarcoma/primitive Neuroectodermal tumor (ES/PNET) developed in the small intestine: a case report. Clin Pediatr Hematol Oncol. 2017;24(2):162

11. Yagnik VD, Dawka S. Extraskeletal Ewing's sarcoma/peripheral primitive neuroectodermal tumor of the small bowel presenting with gastrointestinal perforation. Clin Exp Gastroenterol. 2019;12:279-85.

12. Batziou C, Stathopoulos GP, Petraki K, Papadimitriou C, Rigatos SK, Kondopodis $\mathrm{E}$, et al. Primitive neurectodermal tumors: a case of extraosseous Ewing's sarcoma of the small intestine and review of the literature. J BUON. 2006;11(4):519-22.

13. Peng $L$, Yang $L$, Wu N, Wu B. Primary primitive neuroectodermal tumor arising in the mesentery and ileocecum: a report of three cases and review of the literature. Exp Ther Med. 2015;9(4):1299-303.

14. Kim D-W, Chang HJ, Jeong JY, Lim S-B, Lee J-S, Hong EK, et al. Ewing's sarcoma/primitive neuroectodermal tumor (ES/PNET) of the small bowel: a rare cause of intestinal obstruction. Int J Color Dis. 2007;22(9):1137-8.

15. Horie $Y$, Kato M. Peripheral primitive neuroectodermal tumor of the small bowel mesentery: a case showing perforation at onset. Pathol Int. 2000; 50(5):398-403.

16. Balasubramanian B, Dinakarababu E, Molyneux AJ. Primary primitive neuroectodermal tumour of the small bowel mesentery: case report. Eur J Surg Oncol. 2002;28(2):197-8.

17. Sarangarajan R, Hill DA, Humphrey PA, Hitchcock MG, Dehner LP, Pfeifer JD. Primitive Neuroectodermal tumors of the biliary and gastrointestinal tracts: Clinicopathologic and molecular diagnostic study of two cases. Pediatr Dev Pathol. 2001;4(2):185-91.

18. Boehm R, Till H, Landes J, Schmid I, Joppich I. lleoileal intussusception caused by a Ewing sarcoma tumour. An unusual case report. Eur J Pediatr Surg. 2003;13(4):272-5.

19. Rodarte-Shade M, Palomo-Hoil R, Vazquez J, Ancer A, Vilches N, FloresGutierrez JP, et al. Primitive Neuroectodermal tumor (PNET) of the small bowel in a young adult with lower gastrointestinal bleeding. J Gastrointest Canc. 2012;43(S1):243-5.
20. Vignali M, Zacchè MM, Messori P, Natale A, Busacca M. Ewing's sarcoma of the small intestine misdiagnosed as a voluminous pedunculated uterine leiomyoma. Eur J Obstet Gynecol Reprod Biol. 2012;162(2):234-5.

21. Liao Y-S, Chiang I-H, Gao H-W. A mesenteric primary peripheral Ewing's sarcoma/primitive neuroectodermal tumor with molecular cytogenetic analysis: report of a rare case and review of literature. Indian J Pathol Microbiol. 2018;61(2):248-51.

22. Cantu C, Bressler E, Dermawan J, Paral K. Extraskeletal Ewing sarcoma of the jejunum: a case report. Perm J. 2019;23.

23. Sethi B, Smith GT. Primary primitive neuroectodermal tumour arising in the small bowel. Histopathology. 2007;50(5):665-6.

24. Kushner BH, Hajdu SI, Gulati SC, Erlandson RA, Exelby PR, Lieberman PH. Extracranial primitive neuroectodermal tumors. The Memorial SloanKettering Cancer Center experience. Cancer. 1991;67(7):1825-9.

25. Liu Z, Xu Y-H, Ge C-L, Long J, Du R-X, Guo K-J. Huge peripheral primitive neuroectodermal tumor of the small bowel mesentery at nonage: a case report and review of the literature. World J Clin Cases. 2016;4(9):306-9.

\section{Publisher's Note}

Springer Nature remains neutral with regard to jurisdictional claims in published maps and institutional affiliations.
Ready to submit your research? Choose BMC and benefit from:

- fast, convenient online submission

- thorough peer review by experienced researchers in your field

- rapid publication on acceptance

- support for research data, including large and complex data types

- gold Open Access which fosters wider collaboration and increased citations

- maximum visibility for your research: over $100 \mathrm{M}$ website views per year

At BMC, research is always in progress.

Learn more biomedcentral.com/submissions 